\title{
Investigating pre-service teachers' informally-developed online professional learning networks
}

\author{
Matthew Kearney, Damian Maher \\ STEM Education Futures Research Centre, University of Technology Sydney \\ Lien Pham \\ Graduate Research School, University of Technology Sydney
}

\begin{abstract}
This study investigates how final year pre-service teachers (PSTs) from several countries use social media to support their online professional learning network (PLN) activities. Adopting a mixed-methods approach, it uses a global survey and interview methods to generate fresh insights into PSTs' informally-developed online PLN practices and their perceived benefits of these self-initiated activities. Findings uncover new understandings of contemporary PSTs' patterns of use and configurations of their online PLNs and have implications for their effective transitioning into the teaching profession.
\end{abstract}

\section{Implications for practice or policy:}

- Teacher educators should encourage pre-service teachers to informally develop their own online professional learning networks to leverage a range of benefits, driven by the authentic, diverse and accessible nature of ideas and materials encountered in these spaces.

- Pre-service teachers need affirmation and support to be confident, active participants in their chosen online professional learning network spaces, especially in networks shared with more experienced, practising teachers.

Keywords: teacher education; professional learning, online professional learning networks, social media, mixed method

\section{Introduction}

Professional learning networks (PLNs) are defined by Trust, Carpenter, and Krutka (2018) as "complex amalgams of people and organisations, face-to-face and digital spaces, and cognitive and technological tools that can support continuous learning and professional growth" (p. 1). Underpinned by the premise that learning is a social process (Vygotsky, 1978), teachers' use of social media to support their online PLN practices, can supplement face-to-face PLN strategies to create a broader, enriched learning landscape for knowledge exchange and negotiation of meaning with peers (Jenkins, Purushotma, Weigel, Clinton, \& Robinson, 2009). Teachers' informally developed, self-initiated use of online PLNs is increasingly seen as an effective approach for professional learning (Biddolph \& Curwood, 2016; Tour, 2017; Trust, Krutka, \& Carpenter, 2016), in line with a growing understanding of the value of teachers' autonomy in these practices (Greenhow, Campbell, Galvin, \& Askari, 2018). Given the evidence supporting the benefits of online PLNs for practising (in-service) teachers (ISTs), including use of specific social media platforms such as Twitter, Facebook (FB) and Pinterest (e.g., Carpenter \& Krutka, 2015a), it is imperative for teacher educators and teacher education policy makers, that studies also explore the use of online PLNs by pre-service teachers (PSTs) to provide an enhanced understanding of their practices (Nielsen, Moll, Farrell, McDaid, \& Hoban 2013). Given the ubiquity of social media, it is critical to understand how PSTs participate and perceive their use of social media for their online PLNs (Luo, Sickel, \& Cheng, 2017). Additionally, the potential contribution these activities make to their learning as they prepare for and transition into their teaching careers (Carpenter, 2015) is of significance.

This study aimed to provide a deeper understanding of PSTs' informally developed, online PLNs. It investigated their perceptions of the nature of these self-initiated online networks, and the perceived benefits of their PLN activities. We acknowledge that the social media landscape is a moving target and that platforms are transient in nature (Trust et al., 2016). Nevertheless, it is timely to provide understandings 
of current PSTs' voluntary, multifaceted use of a range of social media platforms supporting their online PLN practices. Hence, this study addressed the following research questions:

- What are PSTs' perceptions of their use of informally developed, online PLNs?

- What are PSTs' perceptions of the benefits of these online PLN activities?

For this study, social media technologies are defined as digital platforms "where users can create, share, and interact with content and each other in online collaborative spaces" (Carpenter \& Krutka, 2015b, p. 29), including social network sites (e.g., FB), microblogging tools (e.g., Twitter), social bookmarking tools (e.g., Delicious), blogging tools (e.g., blogger), media sharing sites (e.g., YouTube) and content curation tools like Pinterest. Online PLN activities are defined as PSTs' use of social media applications to foster interactions with people and resources (Trust et al., 2016) to support their learning as prospective teachers.

\section{Background}

\section{Teachers' informally-developed, online professional learning networks}

In the past decade, there has been ample research into ISTs' online professional learning communities and networks (Lantz-Andersson, Lundin, \& Selwyn, 2018; Macia \& Garcia, 2016). An increasing number of recent studies have focused more specifically on teachers' informally-developed, self-initiated use of social media to support online PLNs (Lantz-Andersson et al., 2018), commensurate with the rapid growth and availability of these social technologies. These studies report on teachers' enhanced experiences of flexibility and autonomy, including self-determination of goals, and control of activities and tools for their professional learning (Greenhow et al., 2018). They indicate a range of benefits for teachers, including a heightened sense of collegiality resulting in sharing of resources and experiences, filtering and curation of new ideas, reflecting on teaching practice and professional support (Macia \& Garcia, 2016). Longer-term benefits include development of teachers' social capital and professional identity (Lantz-Andersson et al., 2018), while the emotional support in these online environments can enhance engagement and a sense of belonging (Davis, 2015).

Teachers' online PLNs can be used to support sharing with (local and global) peers and other experts, and facilitate links with key organisations within and beyond school education contexts (Kearney, PressickKilborn, \& Hunter, 2016). For example, teachers in the Trust et al. (2016) study listed individuals in their local networks such as colleagues and peers, as well as "educators from across the globe with specific expertise ... and people who worked outside the field of education (e.g., writers, scientists)" (p. 22). Many studies show discourse in these online networks is generally non-threatening, courteous and is underpinned by a professional tone, although there has been some criticism that discussions only promote superficial sharing of information and ideas (Lantz-Andersson et al., 2018).

There is evidence of a range of participation practices by teachers in their online PLNs (Prestridge, 2019), including many teachers who adopt passive roles (Macia \& Garcia, 2016). Teachers exhibiting these passive roles lack confidence to post or share, due to lack of time or skills, a fear of being criticised, or concern over copyright and ownership of material (Davis, 2015). Studies analysed by Macia and Garcia (2016) show active participation in these informally developed, online PLNs can be enhanced by face-to-face contact with teachers (e.g., Matzat, 2013).

\section{Pre-service teachers' informally-developed, online professional learning networks}

Most studies with PSTs have so far focused more on formally developed online PLNs, often with set goals, prescribed tools and activities initiated and mediated by teacher educators. For example, researchers have investigated PSTs' use of Twitter-based PLN activities to support collaborative reflection during schoolbased professional experience (Krutka, Bergman, Flores, Mason, \& Jack, 2014; Wright, 2011), mentoring for professional support (Risser, 2013) and connection with educators to provide role models and best practice examples (Kumar \& Leeman, 2013) and enhance discussions, resource gathering and sharing (Carpenter, 2015; Luo et al., 2017). These activities are frequently reported in the context of course requirements, often part of educational technology subjects (Kumar \& Leeman, 2013; Lau, 2018). 
PSTs' participation in online PLN activities can provide opportunities to feel part of a wider community beyond their peers (Krutka et al., 2014; Wright, 2011), to develop knowledge of professional organisations and resources and more generally to make a successful transition from pre-service to in-service teaching (Risser, 2013). However, as most PSTs do not yet identify professionally as teachers, they may be hesitant to interact with in-service teachers (Kearney \& Maher, 2019; Risser, 2013). Studies that have not addressed PSTs' online PLN use as a required part of teacher education coursework have tended to focus on PSTs' perceptions of their more informally-developed social media use for both non-academic (social/recreational) and professional learning purposes, typically collecting data from just one institution (Hughes, Ko, Lim, \& Liu, 2015; Lau, 2018; Nielsen et al., 2013; Sendurur, Sendurur, \& Yilmaz, 2015).

One hundred and nineteen PSTs from one Australian university participated in a study by Nielsen et al. (2013) that examined their use of social media for both non-academic purposes and also as PLN activities for learning about science education in the context of their first-year science methods studies. Rather than frequency of use, the study used self-reports of PSTs' competency levels with social media tools. Participants reported much higher levels of proficiency or competence with these online tools for nonacademic purposes, suggesting a lack of understanding of the potential use of social media for their own learning and work as prospective educators. In a similar study, Sendurur et al. (2015) surveyed 412 PSTs from one Turkish university about their social media use for both social/recreational use and as an online PLN for their learning as prospective teachers. Ninety-five percent of respondents used FB, 59\% used Google+, and $53 \%$ used Twitter; while only 5.2\% used LinkedIn, and 1\% used Pinterest. The most frequently mentioned advantage of using social media for professional learning purposes was the opportunities to communicate with teacher educators and to interact with peers - for example, sharing files and information related to their courses. Lau (2018) examined 212 Hong Kong PSTs from one Hong Kong university in their use of social media for both social/recreational and PLN activities in informal settings, and explored possible relationships with the development of their technological pedagogical content knowledge (TPACK). They found a link with PSTs' development of technological knowledge, and knowledge of teaching with technology. Hughes et al. (2015) used a descriptive survey methodology to investigate 206 PSTs from one US university regarding their use of social media. Nearly all PSTs used a general social networking service (e.g., FB) but about 40\% never used blogs and about $80 \%$ never used Twitter. PSTs' social media use was mostly for non-academic (social/recreational) purposes (especially use of FB and Twitter), and mainly involved consuming content rather than sharing or creating content. Over the 4-year study, use of social media for professional activities as part of an online PLN only rose from 7\% to $22 \%$ of participants. All four of these single institution studies suggested a need for teacher educators to guide PSTs in more effectively utilising these online tools to develop their professional understandings and become more connected educators.

This study excluded PSTs' use of social media for non-academic (social/recreational) purposes and went beyond a single institution investigation. To more extensively scrutinise PSTs' online PLN practices, it used participants from a range of universities across several countries who were more likely to be confident and competent users of social media (see Methodology). In this way, it addressed the need identified by Visser, Evering, and Barrett (2014) and Carpenter (2015) for further studies into PSTs' self-initiated use of online PLNs, examining their multifaceted use of social media platforms supporting their informally developed PLN activities.

\section{Theoretical perspective}

Like many studies in the field of online professional learning (Carpenter \& Krutka, 2015b; Macià \& García, 2016), this study was underpinned by a sociocultural perspective that assumes a dialogical relationship between tools and their users. A tool or technology may be modified according to the ways it is used, and in turn, its design may influence how people might use it (Salomon \& Perkins, 1998). In this study, social media applications were viewed as both a cognitive tool and a cultural medium, and online spaces were considered to be "socially shaped as well as technologically determined" (Lantz-Andersson et al., 2018, p. 304). Some of the benefits of online PLNs can be linked to the possibilities inherent in different social media tools, such as facilities to conveniently access, sort and curate information and resources, and provide connection with peers to enable sharing locally and beyond. The study took a broad ecological view (Jenkins et al., 2009) of an online PLN as constituting the collective use of all PST's chosen platforms, and the associated interactions and activities they support. It acknowledged the social embeddedness of the 
tools (Salomon \& Perkins, 1998) and the importance of learning from social participation (Vygotsky, 1978) and interactions across a tapestry of online spaces and contexts.

\section{Methodology}

The study design was consistent with other studies in this field (e.g., Trust et al., 2016; Visser et al., 2014), using a mixed-method approach (Creswell \& Clark, 2017) and drawing on interpretive study traditions (Erickson, 1986) to investigate PSTs' reported practices with their self-initiated online PLNs. The first stage involved collecting and analysing quantitative and qualitative data from responses to a global online survey of final year PSTs currently enrolled in an initial education course. (The research team felt there was a greater likelihood that final year PSTs would have a more developed online PLN and be more experienced in using it, providing more insightful responses.) The second stage involved interviewing selected volunteer survey respondents, and analysing qualitative data from these interviews. The results from the two strands of data were connected for interpretive analysis.

\section{Stage one: Survey}

In the first stage of the data collection, an online survey of PSTs in their final year was conducted using a non-probability snowball approach. To recruit final year PSTs the researchers wrote to teacher educators in a number of universities in Australia and overseas and asked if they would distribute the survey to their final year PSTs. The survey was also promoted by the researchers via social media using popular PST spaces such as FB groups and Twitter memes (e.g., \#pstchat, \#newteachertribe and \#edtech). Respondents who were not in the final year of their initial teacher education course were bounced from the survey.

The first section of the survey required users to report on their platform-specific links and behaviour patterns (e.g., types of connections, frequency of use, digital content consumption or production tendencies), aiming to explore the nature of the PSTs' online PLN activities, informed by a model for educator PLNs developed by Kearney et al. (2016). Items in the second section were designed to elicit PSTs' perceptions of benefits and challenges of using their online PLN through a combination of closeended questions, open ended questions and Likert scale questions. These items required respondents to consider their online PLNs in a holistic way, mindful of the multifaceted, collective use of all chosen social media platforms they were using as part of their PLN activities. It was made explicit to survey participants that the study was only interested in their use of social media platforms for PLN activities, not for their social or leisure activities. The survey was piloted with 35 PSTs in the final year of their teacher education training program at an Australian university before it was fielded. The final survey was open for 2 months from April to June 2018.

\section{Survey respondents}

Two hundred and six PSTs in their final year participated in the survey. Australia had the highest proportions of respondents (43\%), followed by the United Kingdom (17\%), and Canada (16\%). Other countries included the United States, Hungary, Indonesia, Venezuela, Norway, Belgium, South Africa, Turkey, Ireland, New Zealand, and Hong Kong. Other background information about the survey respondents are shown in Table 1. 
Table 1

Profile of survey respondents

\begin{tabular}{lrr}
\hline & Number of respondents & Percent \\
\hline Type of degree & & \\
\hline Undergraduate & 111 & 54 \\
Postgraduate & 80 & 39 \\
Other & 15 & 7 \\
Total & 206 & 100 \\
\hline Teaching degree & & \\
\hline Primary & 123 & 60 \\
Secondary & 77 & 37 \\
K - 12 & 6 & 3 \\
Total & 206 & 100 \\
\hline Gender & & \\
\hline Male & 40 & 19 \\
Female & 163 & 79 \\
Other & 3 & 2 \\
Total & 206 & 100 \\
\hline Age & & \\
\hline 20 - 30 & 175 & 85 \\
$31-40$ & 14 & 7 \\
$41-50$ & 13 & 6 \\
$>50$ & 4 & 2 \\
Total & 206 & 100 \\
\hline
\end{tabular}

Background questions revealed an overall high level of PST confidence with their use of social media platforms. Proportions of participants who indicated medium or high levels of confidence in their use of social media were $26 \%$ and $49 \%$ respectively. Furthermore, almost all survey respondents reported that they started their online PLN by their own initiative and directed their own PLN activities. PST participants reported that they were not being asked by their university teachers to use social media for pedagogical purposes and were not required to use an online PLN as part of course requirements. Hence, it can be assumed that the degree of PST autonomy in the PLN activities reported in this study is high (akin to activities reported in Kearney \& Maher, 2019).

\section{Stage two: Interviews}

In the second stage of the data collection process, interviews were conducted, based largely on following up key themes identified in the survey. Survey participants were invited to be interviewed and five final year PSTs volunteered: two from Canada (Kyle and Ivan), two from Australia (Claire and Scott), and one from the United States (Gail). The interviews were face-to-face or via video conferencing depending on the location of the participant, and lasted for approximately 30 minutes each.

\section{Data analysis}

The statistical analysis of the multiple-choice survey responses was conducted in two steps. First, descriptive statistics (Field, 2009) were used to identify the overall distribution of various items and demographic information of participant. Second, bivariate analysis was employed to identify clusters and group differences between items (Field, 2009). No apparent variation between groups was identified. In addition, due to the non-random sample, that is respondents self-selected to the study, no further statistical analysis was warranted. Given the study's exploratory approach underpinned by an interpretivist paradigm, and that participants self-reported, no specific validation strategy was employed in the statistical analysis. In items where platform-specific data was collected, an average across platforms was calculated and used in some instances in reporting.

Thematic analysis was used to analyse the interview data and open-ended questions from the survey. Six phases were used including becoming familiar with the data, generating initial codes and categories of codes, searching for themes, reviewing themes, defining and naming themes, and writing up the results 
(Braun \& Clarke 2006). Coding was conducted using topics from the survey and interviews, including PSTs' rationale for choosing social media platforms, the scope of their networking and interactions, and their perceived benefits of using a PLN. Inter-coder reliability checking was conducted between the first two authors at each phase to ensure consistent coding, categorising and identifying of themes. The final stage of analysis involved triangulation of emerging themes across the qualitative and quantitative sources.

\section{Findings}

Findings are reported in two sections that align with the two research questions. The first sub-section provides a snapshot of PST participants' online PLN configurations and their patterns of behaviour, drawing on quantitative and qualitative data. The second sub-section focuses on PSTs' perceived benefits of their online PLN activities, reporting on major themes that draw mainly on qualitative data. Pseudonyms are used throughout the paper to protect interview participants' identities.

\section{Patterns of use and configurations}

Types of social media platforms and rationale for choice

PSTs used a range of social media platforms for their PLN activities: 10 respondents $(5 \%)$ were using one platform, 24 respondents $(12 \%)$ were using two platforms, and 172 respondents $(83 \%)$ were using three or more platforms. The types of platforms that respondents were using for their online PLNs are shown in Figure 1. The two most popular platforms were Pinterest (80\%) and FB (78\%).

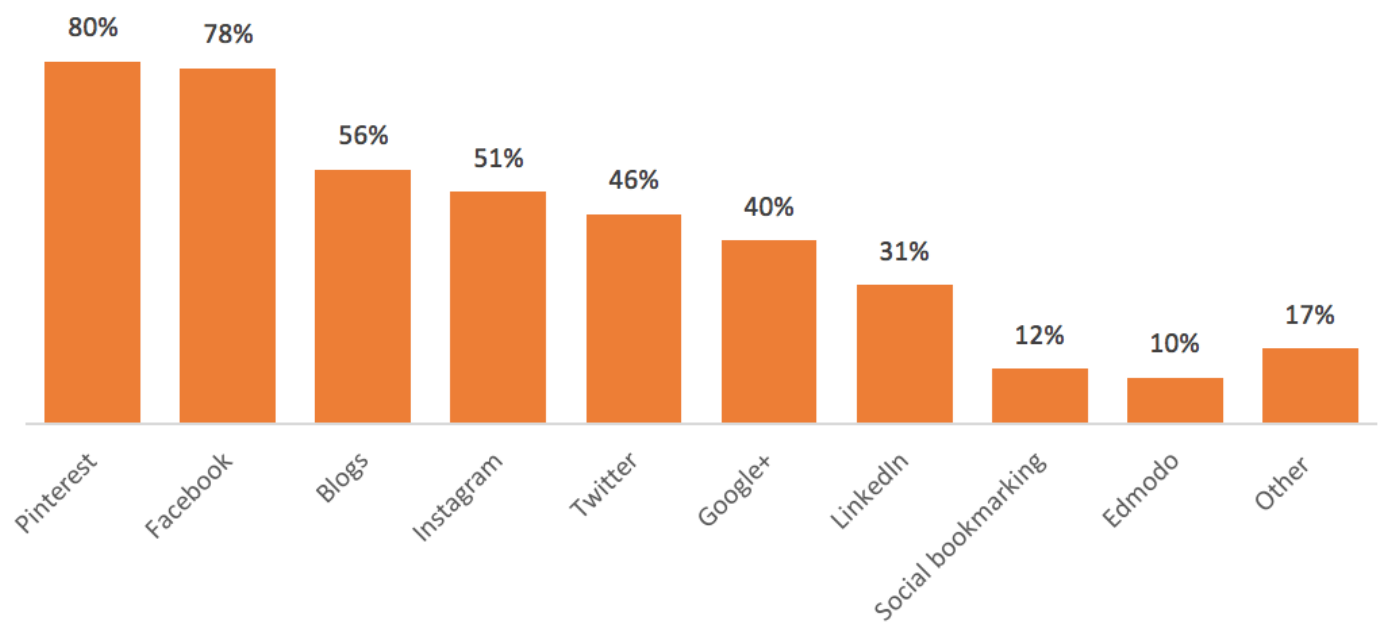

Figure 1. Proportions of respondents using each social media platform as part of their PLN $(\mathrm{n}=206)$

Interview data in our study revealed insights into PSTs' rationales for choosing these platforms. They prioritised platforms that offered seamless access to information and people, and platforms that facilitated meaningful discussion, collaboration and a sense of community. Both Kyle and Scott emphasised in their interviews that they chose platforms that potentially leveraged meaningful, focussed discussion around specific topics, supporting longer, more considered responses. For instance, Kyle believed that his Canadian teacher education course did not emphasise collaboration and hence he chose platforms that he perceived as optimising interactions with other PSTs and ISTs.

PSTs' choice of platforms for their PLN activities were influenced by platforms they were already comfortable using from their social/recreational networks, or by the platforms already used by educators whom they had met face-to-face and wanted to follow in their online PLN. Gail said in her interview that she used Twitter because she was familiar with it from her personal use, and discovered teachers who used it during her first professional experience:

In the first school I did my prac in, a lot of teachers had Twitter. One teacher had a very active twitter account professionally. The school also used it and some of the people I most interact with are people from that first placement. (Gail, interview) 
Ivan initially chose the Twitter platform to enable follow-up discussion with other Twitter users he had met at education conferences and at his professional experience school, while Claire's choice of the FB platform was initially influenced by the existing accounts of the teachers and PST peers at university whom she already knew: "These initial connections seemed 'natural' ... they incorporated connections from practicum and personal (teacher) friends". Finally, Scott reported that his local maths teachers' association had made a positive impact on him and how his membership of this organisation's FB group was a direct follow up from his attendance at a (face-to-face) conference organised by this group.

Consumption and generative behaviour patterns

The survey asked about the extent to which respondents mainly consumed (read, view etc.) or produced content (posts, replies etc.) in each platform of their online PLN. There was an overall trend of PST participants mainly consuming content, as shown in Table 2. On average across platforms, 56\% of PSTs reported that they were mainly consuming content, $5 \%$ were mainly producing content, and $26 \%$ were mainly consuming and producing, or prosuming (Carpenter \& Krutka, 2015b, p. 35) digital content, while $13 \%$ were unsure. The PSTs' behaviour was predominantly passive, revealing a reluctance to share or post in their PLN platforms.

Table 2

Proportions of respondents in each platform that indicated they mainly consume, produce, or consume and produce (prosume) content $(n=206)$

\begin{tabular}{lrrr}
\hline & Mainly consume & Mainly produce & $\begin{array}{c}\text { Mainly consume } \\
\text { and produce }\end{array}$ \\
\hline Google + & $41 \%$ & $6 \%$ & $34 \%$ \\
Social book marking & $42 \%$ & $13 \%$ & $12 \%$ \\
LinkedIn & $52 \%$ & $5 \%$ & $17 \%$ \\
Edmodo & $55 \%$ & $5 \%$ & $25 \%$ \\
Instagram & $55 \%$ & $5 \%$ & $35 \%$ \\
Twitter & $58 \%$ & $1 \%$ & $35 \%$ \\
Facebook & $60 \%$ & $4 \%$ & $34 \%$ \\
Blogs & $73 \%$ & $5 \%$ & $16 \%$ \\
Pinterest & $85 \%$ & $2 \%$ & $10 \%$ \\
\hline
\end{tabular}

Over two-thirds of Pinterest and Blog users were mainly consuming content, while Google+, Instagram, Twitter and FB users were more likely to self-report their main behaviour as either producing or prosuming content (though consuming behaviours were still prevalent even amongst these latter four platforms).

Qualitative data revealed a strong link between the PSTs' propensity to consume information and ideas, rather than share (or produce) content in their online PLN, and their lack of confidence and feelings of intimidation in teacher PLN spaces. Having confidence to share posts and resources via their online PLNs with ISTs and prospective employers was daunting for many PSTs and led them to exhibit these predominantly passive behaviours. As novice teachers lacking experience, they were reluctant to critique or react to experienced teachers' views and perceived that they "didn't have much to offer" in debates and discussions involving ISTs. In her interview, Gail said: "Even though I have had classroom experience I didn't feel qualified to always contribute". Survey participants expressed similar concerns:

The main challenge as a pre- service teacher, is having the confidence to produce content for others and believing that we have something valuable to offer, other than just consuming content.

We are still trainees and not the finished article. For this reason, I feel that I personally would not feel comfortable, in my training year, posting something on a Facebook group for teachers sharing their resources. 
However, when asked about their future plans with their PLNs (after graduation), many survey participants expressed ambitions of changing their predominantly passive online behaviour to be more generative. Two sample responses were:

At the moment, I mainly 'consume' content, as I become more comfortable and familiar with teaching I hope to add to and give back to the greater teaching community and upload my own content/ views.

I would like to create my own teacher's blog which is connected with my LinkedIn, Twitter and Instagram account to share my own ideas.

Connections and scope

PSTs' connections with individuals and organisations in their online PLN are shown in Figure 2. Overall, PSTs prioritised links to individuals over organisations, especially peers in their own course and other universities as well ISTs and teacher education staff. Most nominations in the "Others" individual category were from outside of school education, and included disciplinary experts and education consultants.

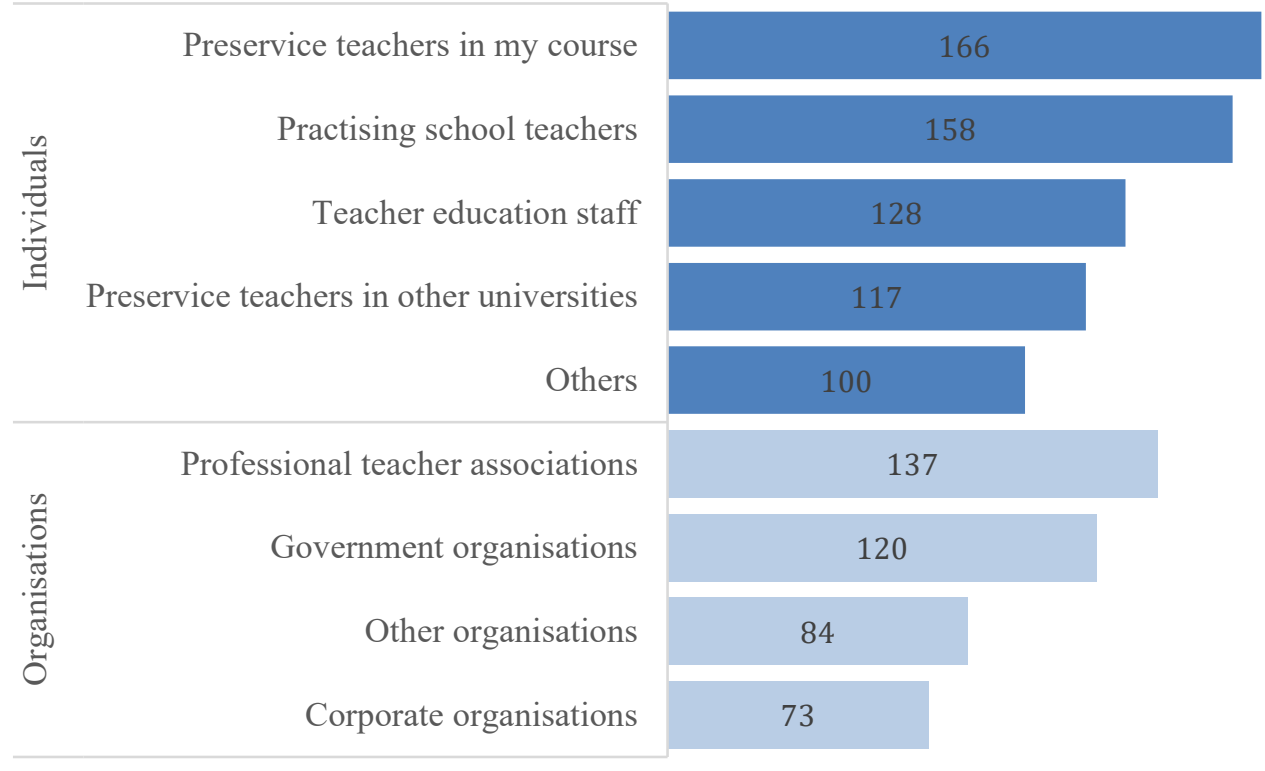

Figure 2. Number of respondents connecting to different types of individuals and organisations across platforms $(\mathrm{n}=206)$

Respondents connected with peers, ISTs and professional organisations more than other types of individuals or organisations across all platforms. There were fewer connections with corporations compared with professional teacher associations and government organisations. Links to professional teacher associations were the most popular type of connection with respondents who used FB, Instagram, Blogs, Pinterest and Google+. Nominations in the "Others" organisations category were from both inside and outside of school education. Organisations within school education included union groups, relief and casual teacher groups, parent groups, school board groups and education department groups. Organisations external to school education included community groups such as sporting communities, museums and galleries.

Figure 3 shows the extent of PSTs' networking in each platform. The proportions of respondents that were connecting to three or more types of people and organisations in each platform are shown in this figure. FB, Twitter and Instagram users were connecting with the widest range of people types. FB and Twitter also had the highest proportions of respondents that were connecting to three or more different types of organisations. 


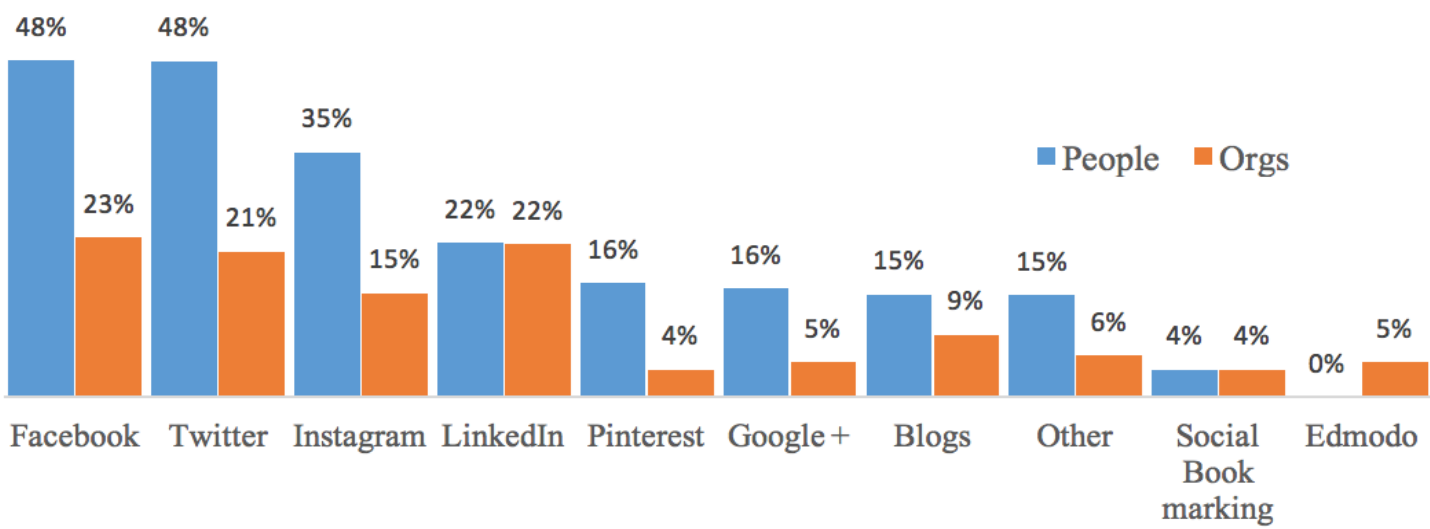

Figure 3. Proportions of respondents that were connecting to three or more types of people and three or more types of organisations, by social media platform $(n=206)$

Overall, users of the FB, Twitter and Instagram platforms self-reported more proactive and generative online PLN behaviour patterns, such as making diverse connections (see Figure 3) and producing content (see Table 2).

Proximity of networking

Qualitative data revealed trends in how widely PSTs were networking. There was general acknowledgement by PSTs that using an online PLN offers an opportunity to link up with people and groups beyond their immediate university course. Sample survey comments were:

It offers wider learning experiences by interacting with people internationally rather than just the university lecturers on my course.

I think that it helps to expand our horizons to teaching methods, environments, and opportunities outside what we normally see at our own university.

PSTs particularly appreciated the diverse contexts of in-service teachers in their networks beyond their local context. One survey respondent appreciated "learning about how best practices implemented in classrooms near and far"; while another PST survey participant enjoyed "discovery of places and schools working differently".

Interviewees emphasised that links beyond their university and school placement contexts facilitated access to views that were different from those encountered in more familiar local contexts. Kyle wasn't satisfied with what he was encountering in his course or observing on his professional experience, so he felt compelled to "reach out and open up to communities online and see what other people in the world are doing". His PLN activities focused on the theme of progressive teaching methods but he needed to pursue this interest beyond his university course:

I'm not seeing them [progressive teaching strategies] from any of my cohort members or any of my associate teachers. I'm only seeing them from these Education content curators on the Internet. I'm not seeing them local. (Kyle, interview)

PST interviewees emphasised links within their own state or country. Claire was interested mainly in national agendas, while Gail said that most of her links were US-based: "The organisations I am on are national specific ones and from the local school district. There are also history teacher ones, like the Smithsonian museum networks". While Ivan, a Canadian PST, liked to focus his connections "local but not too local", stating in his interview:

It's easier to connect with teachers in Canada because the curriculum is similar. It would be difficult to use that knowledge in other countries. By connecting with teachers in Canada I find I don't have to explain the lingo. In the UK and US it is different [professional] language, 
different words. I also connect with publishing houses like the Canadian wildlife foundation. (Ivan, interview)

When asked about their future online PLN plans in a survey item, PSTs expressed a desire to extend the scope of their PLNs when they become ISTs, both locally and internationally.

\section{Perceived benefits}

The PSTs' responses to open-ended questions about the benefits of using online PLNs supported the broad themes of developing a deeper understanding about teaching practices and insights into the teaching profession. They appreciated the relevance and wide range of new and tested teaching ideas and resources, and perceived their online PLNs as a source of support and collegiality.

Developing an awareness and understanding of teaching strategies and resources

PSTs' perceived that their online PLN activities exposed them to a range of relevant, inspiring teaching ideas and facilitated gathering of new resources for their current and future teaching, often in a timely way. They reported that their online PLN activities assisted them in developing a better understanding of teaching strategies. Sample responses were:

Having Twitter was an eye-opener for me as I saw so many teachers on board from new teachers starting out to veteran teachers sharing their experiences to famous teachers and their achievements across the academic profession. Their insight was invaluable in helping me develop my own teaching methods that I hope to implement in my future classrooms.

The main benefits are gaining new ideas, strategies, and skills for teaching. This may include specific resources for various subjects, or more generic skills and attitudes to help me become a better teacher.

Like the survey participants, Claire reported in her interview that she drew inspiration from the ISTs she followed in her PLN, for example, from "the activities they have shared, how they are making learning meaningful".

PSTs highlighted the range of topics that their online PLNs exposed them to, informing their understanding of teaching approaches. Frequently cited topics mentioned by survey participants were class and behaviour management strategies, technology-mediated teaching strategies, and approaches in inclusive education. Kyle's interest was in progressive teaching strategies that went beyond the "textbook formula approaches" he was seeing in schools: "I'm really excited to be a teacher in the $21^{\text {st }}$ century because I get to start looking at how to advance and push education further with these [more progressive] activities that I've been able to derive from my PLN". Similarly, Scott talked enthusiastically in his interview about his passion for problem-based learning (PBL) in maths education and said he had learned much from his PLN activities focusing on this theme. Furthermore, his PLN activities helped him to confirm his own teaching beliefs as he grappled with the dissonance between what he was being taught at university and what he observed on his professional experience. He found that teachers at his professional experience school were not enthusiastic about the PBL approaches being espoused by his lecturers at university. He used his PLN to gauge other teachers' views about PBL and this helped to reconcile these differences and clarify his own teaching beliefs:

It's reassuring me that there are 'teachers out there' who agree with what I've been told at university. Despite the fact that I haven't yet seen them in a school, I have seen them [via his PLN] in contexts outside schools and pushing an approach similar to what the uni is 'pushing'. To know that it [the PBL approach] is 'real'! (Scott, interview)

PSTs appreciated that the teaching ideas and materials accessed through their online PLNs typically came from real teachers and therefore were perceived as realistic and tested. One survey respondent said a critical aspect of using PLNs was "getting advice from more seasoned professionals", while another PST emphasised "being able to 'build off' what has worked for other teachers in the past". Another survey respondent reported: 
Twitter has given me access to someone who has gone through the experience already and was sharing their thoughts, ideas and experiences in a 'real' and 'honest' way with the opportunity to access resources for free that were backed up by real experiences and results.

PSTs recognised that their online PLNs made it easier to find people relevant to their interest or problem. They particularly appreciated the convenient access to these teaching ideas and materials during professional experience. The ability to conveniently search for and adapt lesson ideas for their practicum classes, often under the pressure of short preparation timelines, was a commonly highlighted benefit of their PLNs.

Providing support and collegiality

PSTs' perceived that their online PLN activities provided them with much needed support and collegiality. For example, Kyle stated in his interview: "You feel like you're part of the community. You feel like you're part of a collaborative process". As discussed previously, they deliberately chose platforms that potentially facilitated meaningful discussion and a sense of community, so this perceived benefit was unsurprising. Nevertheless, PSTs felt that their online PLN activities were indeed enhancing their professional conversations and sense of collegiality. For example, a survey respondent explained how use of Twitter had facilitated professional interactions with inspiring educators:

I have learned that Twitter is a great outlet for connecting to fellow colleagues. I have been able to stay in touch with principals or educators I have either previously worked with or met that I admire. Through interactions on Twitter, I am able to continue to learn from those educators.

While Gail appreciated the opportunity to use her online PLN to extend face-to-face conversations with school colleagues during her professional experience:

One of the advantages is that there was not always time during the school day to talk about ideas or issues and a person would post an idea or article and you could start a conversation about what people in my school were thinking about those issues. (Gail, interview)

Participants discussed how their online PLNs provided peer support to address feelings of isolation or anxiety, especially during professional experience. Claire said she received support through her FB posts during her professional experience: "A lot of my connections gave me emotional support around 'being on 'prac' ... offering help and feedback. It's nice to know you're not alone. It helps with any feelings of being overwhelmed". Other participants expressed similar sentiments:

[My online PLN gave me] Reassurance I am in good company when I am angered and frustrated by aspects of school environments.

I know teachers I can connect with and talk about not so good experiences and it's good to see sometimes other people are struggling and that there is a community and you know you are not alone. (Gail, interview)

Other perceived benefits

Survey participants mentioned that their online PLN activities gave them a unique insight into the teaching profession in areas that were not covered formally in their teacher education course. For example, an enhanced awareness of teacher language practices, real professional challenges such as stress and workload management, and current discussions and debates on education trends, events, policies and research of interest. One survey respondent said that these insights helped PSTs to essentially "humanize the profession". For example, Gail appreciated being exposed to teachers' professional conversations and language: "I didn't really know how teachers connected or spoke in real time so I think being an observer in the communities shows me what is possible that I will be able to utilize". While Claire gained insights into "life as a teacher" from reading and listening to "stories and testimonies", stating that her online PLN activities gave her "an in-depth understanding of complex Australian education systems, jargon, accreditation and training and language around this area". 


\section{Discussion and implications}

The first part of this study examined the patterns of use and configurations of PSTs' informally developed online PLNs. Similar to studies of ISTs' PLN practices (e.g., Trust et al., 2016), the PSTs in this study reported on their use of extensive online networks consisting of a wide range of connections to people and organisations (see Figure 2). The large majority of PSTs were using three or more social media platforms for their online PLN, with Pinterest and FB the most popular applications. They were linking to a range of types of people and organisations, most commonly with peers, ISTs and professional teacher groups. PSTs appreciated that their online PLN activities offered opportunities to interact with teachers and others beyond their immediate university environment, and reported on a tendency to make local and national links. They anticipated a greater emphasis on international connections after leaving university and becoming early career teachers. A depiction of a PSTs' online PLN is presented below in Figure 4.

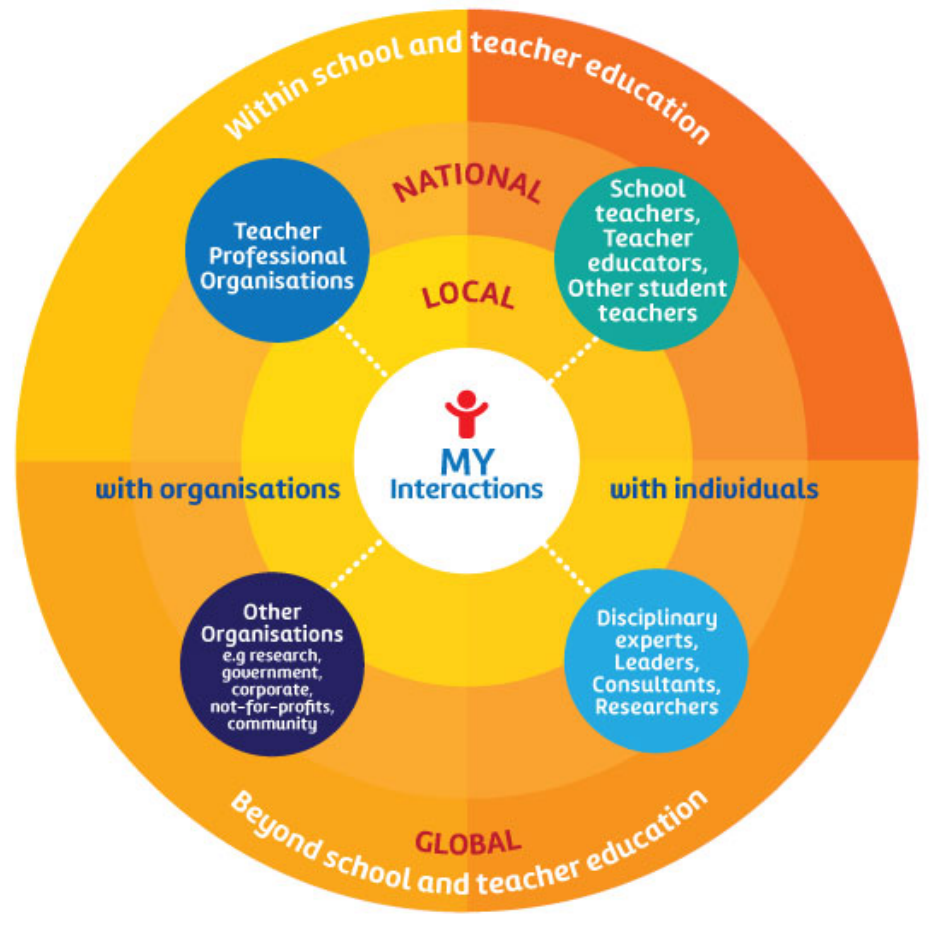

Figure 4. Online PLNs from a pre-service teacher's perspective. (Adapted from Kearney et al., 2016, p. 31)

Underpinned by the fundamental importance of social aspects of learning (Vygotsky, 1978) in these online spaces, this depiction emphasises PSTs' interactions with peers, teachers and other experts from a range of relevant disciplinary contexts. Adaptations from the depiction of practising teachers' PLNs in Kearney et al. (2016) include an additional "national" (middle) layer of networking (e.g., see previously presented interview data from Claire, Gail, Kyle, and Ivan), the addition of "school teachers", "teacher educators", and "student teachers" in the upper right quadrant, and the addition of "community groups" as an example of organisations in the lower left quadrant.

The use of social media applications by PSTs in our study (see Figure 1) is difficult to compare with other studies of PSTs discussed earlier in this paper (eg., Sendurur et al., 2015). Their patterns of use statistics were typically drawn from only one institution and also included PSTs' use of social media for nonacademic (social/recreational) purposes. However, the use of applications by PSTs in our study is somewhat different to trends described in recent IST studies. For instance, the most popular platforms used by ISTs $(\mathrm{n}=503)$ in the recent Trust et al. (2016) study were Twitter $(53 \%)$, Edmodo (26\%), and blogs $(25 \%)$. FB and Pinterest - the two most popular applications in our study ( $80 \%$ and $78 \%$ respectively) - were two of the least popular platforms being used by ISTs in the Trust et al. (2016) study (both 12\%). This incongruence may be simply due to recent changes in popularity of social media platforms, or due to 
different patterns of use in various age groups or countries. Further investigations are needed into how PSTs' choice and use of PLN platforms might optimise their interactions with both peers and ISTs.

The use of the different platforms by PSTs in this study was linked to different types of online behaviour and interactions, as shown in Figure 3. PST users of FB and Twitter were evidently enjoying a more diverse range of connections to people types (peers in and beyond their university course, ISTs and teacher education staff) than PST users of other platforms. While PST users of the Google+, Instagram, Twitter and FB platforms were more likely to be exhibiting more generative behaviours (writing posts, sharing resources etc.), though still at relatively low levels compared to consumption rates. Overall, the PSTs in this study exhibited stronger networked-based learning traits (Downes, 2007; Krutka, Carpenter, \& Trust, 2016), such as making diverse connections and creating content, when using the FB, Twitter and Instagram platforms. We do not advocate techno-deterministic views of these technologies and acknowledge that how these tools are used to support quality interactions is critical to PSTs' socially-mediated learning in these online spaces. However, we recommend further studies - underpinned by a socio-cultural perspective (Salomon \& Perkins, 1998) — to investigate how specific facilities embedded in these tools might leverage and shape PSTs' informally developed online PLN practices.

There was a strong trend of PSTs in this study reporting on mainly consuming digital content in their informally-developed online PLN activities, and evidently a reluctance to share or produce their own content (see Table 2). Like the PSTs in previous studies (e.g., Hughes et al., 2015; Kearney \& Maher, 2019, Luo et al., 2017), participants in this study reported low rates of content generation in these online spaces. They did not feel qualified to share ideas and resources with their more experienced colleagues, and reported on feelings of intimidation from more experienced ISTs. These sentiments of intimidation are somewhat surprising given the generally courteous and non-threatening nature of ISTs' online conversations in these spaces (Lantz-Andersson et al., 2018). However, the formal, professional tone of these same IST conversations (Lantz-Andersson et al., 2018) may be a source of intimidation for PSTs, though this possibility needs confirmation in further studies.

Most participants in this study wanted to continue using their online PLNs after graduation and indeed, aspired to generate and share more content in these spaces when they became ISTs. Nevertheless, there is a danger that some PSTs may be slow to move to a more desirable participative mode of behaviour, and jeopardize missing important professional support in the critical initial years as an IST. Hence, strategies are needed to address PSTs' feelings of inadequacy and intimidation to facilitate their transition to more active online practices during their candidature. To supplement other recommended strategies involving mediation by teacher educators, such as encouraging PSTs' initial immersion in closed, private spaces (e.g., Hughes et al., 2015), less interventionist approaches are also needed, in tune with the self-directed nature of PSTs' informally developed PLNs. For instance, teacher educators' modelling of more generative online behaviours may be influential and further studies are needed into the impact of their online (and offline) PLN practices on PSTs' PLN development.

A major influence on many PSTs' initial participation in their online PLN activities in this study was the influence from ISTs in their professional experience schools. Teacher supervisors and other ISTs supporting PSTs on school placements, and indeed ISTs from other face-to-face encounters such as Teachmeets and Edcamps (Carpenter \& Linton, 2016), as mentioned by Scott in this study, may have a crucial role in supporting PSTs' development of more active online PLN behaviours. For example, affirmation from these ISTs in online PLN spaces (e.g., using replies, comments, likes, re-posts) may enhance PSTs' confidence levels in their interactions with ISTs. Further investigations into the interplay between face-to-face and online approaches to PSTs' informally developed PLN activities, akin to similar studies of ISTs (e.g., Matzat, 2013), may provide a more holistic understanding of their blended practices.

In response to the second research question, the PSTs perceived an enhanced awareness and understanding of teaching strategies, driven by the authentic, diverse and accessible nature of the ideas and materials they encountered in their online PLN activities. Like other PLN studies involving ISTs (e.g., Biddolph \& Curwood, 2016; Trust el al., 2016; ), PSTs reported that their online PLN activities provided collegiality and a sense of community, particularly during professional experience, and more generally provided inspiration to improve their teaching. Contrary to criticism of online PLN activities as only promoting shallow conversations (Lantz-Andersson et al., 2018), PSTs in this study reported on meaningful interactions that led to deeper understandings of teaching strategies and used their online PLNs to clarify 
their pedagogical beliefs. They also developed insights into the teaching profession, including its online sharing culture, language practices and challenges faced by ISTs. These benefits evidenced in this study need to be considered in light of well-known constraints identified in other studies of PSTs' and ISTs' online PLN use, such as the time-consuming nature of these activities (Carpenter, 2015), concern over professional and personal digital footprints, and inherent information management challenges (Carpenter \& Krutka, 2015b; Kearney \& Maher, 2019, Luo et al., 2017).

\section{Limitations}

This study was limited primarily by the recruitment strategy. Potential PST respondents were invited to complete the survey online through the researchers' own professional networks and colleagues' networks. This approach may have resulted in the skew of survey respondents living in English speaking countries. Our recruitment strategy via social media is likely to have attracted participants who are more enthusiastic about their online PLN practices than participants in similar studies where one large cohort from one institution is examined (e.g., Nielsen et al., 2013). Also, the more advanced cohort of PLN users in this study may have held higher expectations and had a tendency to be more critical of their use (Luo et al., 2017). In addition, the methods used in this study only captured self-reported practices and data from one point in time, albeit during PST participants' final year of study. Hence, the sample used in this study is not representative of all PSTs and findings cannot be generalised to the whole PST population.

\section{Conclusion}

This international study makes a contribution to the emerging literature on informally-developed, online PLNs in initial teacher education contexts. Although there are inherent limitations, the study goes beyond a single institution examination of more formally-developed PLNs that is typical of studies in this field. The findings provide valuable insights into PSTs' contemporary use and configurations of their selfinitiated, online PLN activities, and their perceived benefits of these practices. The final year PST participants from several countries reported on their multifaceted, voluntary use of numerous social media platforms in their PLN practices, including diverse connections to people and organisations. Perceived benefits of their online PLN activities included support and collegiality, enhanced understandings of teaching strategies, and deeper insights into the teaching profession. Although PST participants valued the relevant and tested ideas and resources shared by ISTs in their networks, opportunities not typically available in their university courses, they sometimes felt inadequate and intimidated by ISTs in these online spaces, and were subsequently reluctant to make posts and share their own ideas and resources.

There is growing realisation of the value of ISTs' self-directed, online professional learning using social media (Greenhow et al., 2018; Trust et al., 2016) and hence, it is becoming essential for PSTs to enter the workforce with their own well-developed online PLNs and more importantly, with the confidence and competencies to fully participate in these activities. This study provides the groundwork for further research in this area. Other methods beyond self-reporting surveys and interviews could be implemented in future studies, such as artefact analysis of data captured from social media sites (Greenhow et al., 2018), to better understand PSTs' engagement with their online PLNs. The potential mediating roles of ISTs and teacher educators in these activities also need examination, for example, their modelling and support of more proactive online practices. Finally, longitudinal studies akin to Risser's (2013) research are needed to track the development of PSTs' online and face-to-face PLNs as they transition from their final year of studies into early career teaching.

\section{References}

Biddolph, C., \& Curwood, J. S. (2016). \#PD: Examining the intersection of Twitter and professional learning. In M. Knobel, \& J. Kalman (Eds.), New literacies in teacher learning: Professional development and the digital turn (pp. 195-218). New York, NY: Peter Lang.

Braun, V., \& Clarke, V. (2006). Using thematic analysis in psychology. Qualitative Research in Psychology, 3(2), 77-101.

Carpenter, J. P. (2015). Preservice teachers' microblogging: Professional development via Twitter. Contemporary Issues in Technology and Teacher Education, 15(2), 209-234. 
Carpenter, J. P., \& Krutka, D. G. (2015a) Engagement through microblogging: Educator professional development via Twitter. Professional Development in Education, 41(4), 707-728. https://doi.org/10.1080/19415257.2014.939294

Carpenter, J. P., \& Krutka, D. G. (2015b). Social media in teacher education. In M. Niess, \& H. Gillow-

Wiles (Eds.), Handbook of research on teacher education in the digital age (pp. 28-54). Hershey, PA: IGI Global. https://doi.org/10.4018/978-1-4666-8403-4.ch002

Carpenter, J. P., \& Linton, J. N. (2016). Edcamp unconferences: Educators' perspectives on an untraditional professional learning experience. Teaching and Teacher Education, 57, 97-108.

Creswell, J. W., \& Clark, V. K. (2017) Designing and conducting mixed methods research (3rd ed.).

Thousand Oaks, CA: Sage.

Davis, K. (2015). Teachers' perceptions of twitter for professional development. Disability \& Rehabilitation, 37(17), 1551-1558. https://doi.org/10.3109/09638288.2015.1052576

Downes, S. (2007). Learning networks in practice. In D. Ley (Ed.), Emerging technologies for learning (pp. 19-27). Coventry: Becta.

Erickson, F. (1986). Qualitative methods in research on teaching. In M. Wittrock (Ed.), Handbook of research on teaching (pp. 119-161). New York, NY: Macmillan.

Field, A. (2009). Discovering statistics using SPSS. London: Sage Publications Limited.

Greenhow, C., Campbell, D., Galvin, S., \& Askari, E. (2018). Social media in teacher professional development: A literature review. In E. Langran, \& J. Borup (Eds.), Proceedings of SITE International Conference (pp. 2256-2264). Washington, DC: AACE.

Hughes, J., Ko, Y., \& Lim, M., \& Liu, S. (2015). Preservice teachers' social networking use, concerns, and educational possibilities: Trends from 2008 to 2012. Journal of Technology and Teacher Education, 23(2), 185-212.

Jenkins, H., Purushotma, R., Weigel, M., Clinton, K., \& Robinson, A. (2009). Confronting the challenges of participatory culture: Media education for the 21st century. Cambridge, MA: MIT Press.

Kearney, M., \& Maher, D. (2019). Mobile learning in pre-service teacher education: Examining the use of professional learning networks. Australasian Journal of Educational Technology, 35(1), 135-148. https://doi.org/10.14742/ajet.4073

Kearney, M., Pressick-Kilborn, K., \& Hunter, J. (2016). What's in a PLN? Making it count for preservice and early career teachers. Education Review, 5, 30-31.

Krutka D. G., Bergman D. J., Flores R., Mason K., \& Jack A. R. (2014). Microblogging about teaching: Nurturing participatory cultures through collaborative online reflection with pre-service teachers. Teaching and Teacher Education, 40, 83-93. https://doi.org/10.1016/j.tate.2014.02.002

Krutka, D. G., Carpenter, J. P., \& Trust, T. (2016). Elements of engagement: A model of teacher interactions via professional learning networks. Journal of Digital Learning in Teacher Education, 32(4), 150-158.

Kumar, S., \& Leeman, J. (2013). Connecting pre-service teachers and experienced educators: Social media for lifelong learning. International Journal of Technologies in Higher Education, 10(3), 28-41. https://doi.org/10.7202/1035577ar

Lantz-Andersson, A., Lundin, M., \& Selwyn, N. (2018). Twenty years of online teacher communities: A systematic review of formally-organized and informally-developed professional learning groups. Teaching and Teacher Education, 75, 302-315.

Lau, W. (2018). Relationships between pre-service teachers' social media usage in informal settings and technological pedagogical content knowledge. Eurasia Journal of Mathematics, Science and Technology Education, 14(12). https://doi.org/10.29333/ejmste/94228

Luo, T., Sickel, J., \& Cheng, L. (2017). Preservice teachers' participation and perceptions of Twitter live chats as personal learning networks. TechTrends, 61(3), 226-235. https://doi.org/10.1007/s11528016-0137-1

Macià, M., \& García, I. (2016). Informal online communities and networks as a source of teacher professional development: A review. Teaching and Teacher Education, 55, 291-307.

Matzat, U. (2013). Do blended virtual learning communities enhance teachers' professional development more than purely virtual ones? A large scale empirical comparison. Computers \& Education, 60(1), 40-51.

Nielsen, W., Moll, R., Farrell, T., McDaid, N., \& Hoban, G. (2013). Social media use among pre-service primary teachers. International Journal of Instructional Technology and Distance Learning, 10(8), 313. 
Prestridge, S. (2019). Categorising teachers' use of social media for their professional learning: A selfgenerating professional learning paradigm. Computers \& Education, 129, 143-158. https://doi.org/10.1016/j.compedu.2018.11.003

Risser, H. S. (2013). Virtual induction: A novice teacher's use of Twitter to form an informal mentoring network. Teaching \& Teacher Education, 35, 25-33.

Salomon, G., \& Perkins, D. (1998). Individual and social aspects of learning. Review of Research in Education, 23(1), 1-24.

Sendurur, P., Sendurur, E., \& Yilmaz, R. (2015). Examination of the social networking sites usage patterns of pre-service teachers. Computers in Human Behavior, 51, 188-194. https://doi.org/10.1016/j.chb.2015.04.052

Tour, E. (2017). Teachers' self-initiated professional learning through personal learning networks. Technology, Pedagogy and Education, 26(2), 179-192. https://doi.org/10.1111/lit.12101

Trust, T., Krutka, D. G., \& Carpenter, J. P. (2016). Together we are better': Professional learning networks for teachers. Computers \& Education, 102, 15-34. https://doi.org/10.1016/j.compedu.2016.06.007

Trust, T., Carpenter, J. P., \& Krutka, D. G. (2018). Leading by learning: exploring the professional learning networks of instructional leaders. Educational Media International, 55(2), 1-16. https://doi.org/10.1080/09523987.2018.1484041

Visser, R. D., Evering, L. C., \& Barrett, D. E. (2014). \#TwitterforTeachers: The implications of Twitter as a self-directed professional development tool for K-12 teachers. Journal of Research on Technology in Education, 46(4), 396-413. https://doi.org/10.1080/15391523.2014.925694

Vygotsky, L. (1978). Mind in society. Cambridge, MA: Harvard University Press.

Wright, N. (2011). Tweeting to reflect on teaching practicum experiences. Waikato Journal of Education, $16(1), 65-76$

Corresponding author: Matthew Kearney, matthew.kearney@uts.edu.au

Copyright: Articles published in the Australasian Journal of Educational Technology (AJET) are available under Creative Commons Attribution Non-Commercial No Derivatives Licence (CC BY-NC-ND 4.0). Authors retain copyright in their work and grant AJET right of first publication under CC BY-NC-ND 4.0.

Please cite as: Kearney, M., Maher, D., \& Pham, L. (2019). Investigating pre-service teachers' informallydeveloped online professional learning networks. Australasian Journal of Educational Technology, 36(1), 21-36. https://doi.org/10.14742/ajet.4766 